\title{
Modellus: Animações Interativas Mediando a Aprendizagem Significativa dos Conceitos de Física no Ensino Médio
}

\author{
Modellus: Interactive Animations Mediating the Meaningful Learning of Physics Concepts \\ in High School
}

\author{
Gustavo H. Santos \\ Centro de Pós-Graduação e Pesquisa - FVC \\ Rua do Salete, 50, Barris \\ Salvador - BA - 40070-200 \\ Lynn Alves \\ Centro de Pós-Graduação e Pesquisa - FVC \\ $e$ \\ Departamento de Educação - UNEB \\ Rua Silveira Martins, 2555 \\ Salvador - BA - 41195-001 \\ Marcelo A. Moret* \\ Centro de Pós-Graduação e Pesquisa - FVC \\ $e$ \\ Departamento de Fúsica - UEFS \\ Campus Universitário, s/n, Km 03, BR 116 \\ Feira de Santana - BA - 44031-460
}

\begin{abstract}
As dificuldades que alunos do ensino médio possuem na aprendizagem dos conceitos da Física são conhecidas. A utilização de métodos tradicionais de ensino e ausência de meios pedagógicos modernos constituem-se razões deste problema. Neste artigo, apresentamos quatro animações interativas, desenvolvidas em um ambiente virtual de aprendizagem computacional. Utilizamos o software Modellus como ferramenta mediadora da aprendizagem significativa dos conceitos de Física, com os alunos do ensino médio do Colégio Militar de Salvador. A criação do Laboratório Virtual e impacto das simulações no ensino/aprendizagem foram representadas em gráficos, estes baseados em um questionário respondido pelos alunos, durante as atividades.
\end{abstract}

Palavras-chave: Laboratório Virtual, Ensino de Física, Aprendizagem Significativa, Modelagem Computacional, Animações Interativas.

High school students difficulties in learning Physics concepts are known. The usage of traditional teaching methods and the lack of modern pedagogical resources are some reasons for this problem. In this article, we presented four interactive animations, developed in a virtual learning environment, from computational modeling. We used Modellus software as a mediating tool of Physics concepts meaningful learning to high school students of Colégio Militar de Salvador (Salvador Military School). The creation of the Laboratory Virtual (Virtual Laboratory) and the teaching-learning simulations impact were represented in graphs, based on a quiz answered by the students during the activities.

Keywords: Virtual Laboratory, Physics Teaching, meaningful learning, computational modeling, interactive animations.

\footnotetext{
*Endereço Eletrônico: moret@uefs.br
} 


\section{INTRODUÇÃO}

Por ser uma ciência experimental e de conceitos abstratos, a Física torna-se uma disciplina peculiarmente de difícil compreensão para os alunos. No ensino médio, tal característica apresenta proporções significativas, o que dificulta uma associação com o mundo real e, por conseguinte, o interesse pelo aprendizado da disciplina.

Neste trabalho, realizado com alunos do ensino médio do Colégio Militar de Salvador e durante o $2^{\circ}$ semestre do ano letivo de 2005, aplicamos, a partir do uso de tecnologia computacional, quatro simulações de fenômenos físicos.

$\mathrm{Na}$ seção 2, tratamos de alguns aspectos relacionados à Física no ensino médio. Para Hestenes [1], os métodos tradicionais de ensinar Física são inadequados. Conceitos complexos e difíceis de visualizar, quando apresentados apenas sob uma metodologia verbal ou textual, costumam demonstrar falhas na aprendizagem [2]. A partir de Novas Tecnologias Educacionais (NTE) e Tecnologia da Informação (TI), novas possibilidades de construção de animações interativas surgiram como ferramentas mediadoras para o ensino/aprendizagem da Física, o que discorremos na seção 3 . O uso dos Ambientes Virtuais de Aprendizagem, como o Modellus, promove uma abordagem construtivista e enquadra-se no conceito de ferramentas computacionais as quais são capazes de auxiliar na construção do conhecimento [3], e podem ser usadas para dar sentido ao novo conhecimento por interação com significados claros, estáveis e diferenciados, previamente existentes na estrutura cognitiva do aprendiz [4]. Na seção 4, apresentamos as quatro animações construídas no software Modellus, onde procuramos explorar todos os recursos da ferramenta na busca da melhor interatividade entre o experimento e o aluno. Por fim, dedicamos a seção 5 para apresentação e discussão dos resultados. Estes, em formato percentual, indicam a importância da interatividade do aluno com os objetos de conhecimento, o melhor entendimento dos conceitos de Física tratados em sala de aula, a não utilização dos micro- computadores domésticos para realização de experimentos virtuais e a expectativa de ensino/aprendizagem, mediado por computador, em torno de outras disciplinas. Como forma de coleta dos dados, aplicamos a técnica de inquirição utilizando a escala de atitude do tipo Likert [5], juntamente com um levantamento de opinião.

\section{FÍSICA NO ENSINO MÉDIO}

Segundo Borges [6], o ensino tradicional de ciências, do ensino fundamental ao ensino superior, tem se mostrado pouco eficiente, seja tanto na perspectiva dos estudantes e professores, quanto das expectativas da sociedade. Para Veit e Teodoro [3], na prática, Física representa para o estudante, na maior parte das vezes, uma disciplina muito difícil, em que é preciso decorar fórmulas, cuja origem e finalidades são desconhecidas. Os poucos laboratórios existentes e que funcionam, além de representarem elevado custo de montagem e manutenção, costumam, por sua vez, ser utilizados de forma tradicional e limitada, seguindo roteiros prévios e instrucionistas. Um ensino das ciências baseado exclusivamente ou predominantemente em discursos, transmite uma idéia muito incompleta e muito pouco aliciante do que é a ciência e de como ela se constrói. Para Moreira [7], a educação em ciências tem por objetivo fazer com que o aluno venha a compartilhar significados no contexto das ciências, ou seja, interpretar o mundo desde o ponto de vista das ciências, manejar alguns conceitos, leis e teorias científicas, abordar problemas raciocinando cientificamente, identificar aspectos históricos, epistemológicos, sociais e culturais desta área. Com isso, alguns aspectos do ensino e aprendizagem da Física se mostram relevantes, quando se busca um melhor aproveitamento escolar, a exemplo de: metodologias de ensino mais construtivistas; a utilização de meios mais interativos que promovam o desenvolvimento cognitivo dos alunos; a articulação dos conhecimentos prévios, principalmente da matemática relacionados com a 
física, e à formação contínua dos docentes.

Por ser essencialmente experimental, a Física como ciência, surge para explicar os fenômenos naturais, no qual qualquer teoria só tem significado real quando comprovada experimentalmente. Para Moreira e Levandowski [8], o processo de investigação experimental é, essencialmente, um processo através do qual se vai de eventos até respostas a questões formuladas a respeito dos mesmos. Por maior que seja a capacidade de explanação de determinado professor, este defrontará com as dificuldades de expor um fenômeno físico dinâmico a partir de recursos estáticos que dispõem. É quase impossível, usando apenas giz e quadro negro, representar a dinâmica de um evento em uma seqüência de instantâneos como desenhos de uma animação.

O ensino da Física baseado na exposição de teoria e resolução de problemas, denota uma metodologia pouco relacionada com a realidade do aluno, onde este, convencido pelas teorias científicas sem compreendê-las, recebe-as como uma espécie de crença. Em suas orientações, os PCNs procuram dar um novo sentido para o ensino da Física, em construir uma visão voltada para a formação de um cidadão contemporâneo, atuante e solidário, com instrumentos para compreender, intervir e participar na realidade. Também mostram a necessidade de adaptação de novas metodologias para a melhoria da qualidade de ensino ofertado nas escolas.

O surgimento das novas tecnologias baseado no uso do computador, associadas a aparatos pedagógicos fundamentados em paradigmas educacionais, tornam-se poderosos contribuintes ao processo ensino/aprendizagem.

\section{USO DE ANIMAÇÕES INTERATIVAS NA APRENDIZAGEM SIGNIFICATIVA}

Definida como programa de computador que simula os fenômenos modelados matematicamente, onde o aprendiz poderá, através da ação, trocar significados e modificar a anima- ção para atender seus objetivos gerais ou específicos, seja com a apresentação dos reais conceitos, relacionamento entre grandezas, gráficos e referências, o uso de animações interativas busca auxiliar na construção do conhecimento e contextualização em articulação com outras áreas [3].

Segundo Boch et al. [9], um modelo é uma simplificação da realidade que, assim como mitos e metáforas, ajudam a trazer sentido para o nosso mundo onde muitas vezes se afigura repleto de razões inalcançáveis. Dessa forma, um modelo oferece, a seu usuário, uma maneira de compreender o que antes era um problema incompreensível. Ele tenta representar um acontecimento a que se reporta. Quando são relacionados com acontecimentos dinâmicos, os modelos são facilmente perceptíveis se providenciamos uma animação que exiba a sua evolução temporal. Quando um modelo evolui temporalmente e permite uma interação com o usuário, chamamos de animação interativa. Grande parte dos conteúdos de Física das escolas do ensino médio está aportado nos modelos dinâmicos, os quais estabelecem referência matemática entre o tempo e quantidades físicas. Desta forma, a utilização de simulações computacionais para o ensino da Física pode ser vista sob dois aspectos: a animação do movimento em estudo e a representação gráfica; ambos permitem uma melhor compreensão dos aspectos matemáticos e físicos que envolvem o conceito em estudo.

Trabalhos técnicos laboratoriais podem ser planejados para demonstrar cada modelo científico, porém estes são decorrentes da integração de experiências realizadas com diferentes enfoques, ou seja, uma experiência única nem sempre mostra aos estudantes um fenômeno inteiro. Neste caso, uma simulação por computador pode ser a única maneira de ultrapassar o problema. Para Pierre Lévy [10], trata-se de uma tecnologia intelectual que amplifica a imaginação individual e permite aos grupos que compartilhem, negociem e refinem modelos mentais comuns, qualquer que seja a complexidade deles. A simulação é um modo especial de conhecimento, próprio da cultura cibernética vigente. $\mathrm{O}$ maior interesse não é 
o de substituir a experiência, nem o de tomar o lugar da realidade, mas, sim o de permitir a formulação e a exploração rápidas de grande quantidade de hipóteses. A animação interativa tem se configurado como uma possibilidade alvissareira no processo ensino-aprendizagem de Ciências Naturais, de modo geral, e de Física, de modo particular [3, 11]. Segundo Davies [12], simulações e animações oferecem um potencial, sem limites, para permitir que os estudantes entendam os princípios teóricos das Ciências Naturais, a ponto de serem chamados de Laboratórios Virtuais. Essa ferramenta pedagógica é de grande valia para o aumento da percepção do aluno, pois pode incorporar, a um só momento, diversas mídias: escrita, visual e sonora. E, desse modo, potencializa as possibilidades pedagógicas da interação professor-aluno. Para Jimoyiannis e Komis [13], são poucos os alunos que desenvolveram uma significativa capacidade de abstração, e conseqüentemente, um bom número de estudantes têm grande dificuldade em acompanhar certos tópicos dos cursos de Física.

As animações são poderosas aliadas na exposição de fenômenos que variem com o tempo, tornando o processo pedagógico mais direto e mais simples, promovendo o contato dos estudantes com as idéias centrais que se deseja mostrar. Os "experimentos virtuais" além de estarem acessíveis a qualquer instante, podem ficar a disposição dos alunos fora do horário das aulas, uma vez que os roteiros das "experiências" podem ser vivenciados de forma individualizada. Assim, dentro de uma ótica construtivista, um simulador de atividades visa fornecer aos alunos uma experiência direta, fazer hipóteses e observar os efeitos destas hipóteses. O aluno pode executar seu modelo de simulação e observá-lo, modificando os parâmetros como desejar, e realizando novas predições. Uma animação interativa representa a evolução temporal de um modelo da realidade, aceito pela comunidade científica. Tornase possível a exibição da evolução temporal de objetos abstratos em sua representação concreta, já que é inclusiva e genérica quando abre a possibilidade de reunir, em uma exibição, todos os casos de uma determinada categoria [14].
Tais animações interativas enquadram-se no conceito de ferramentas computacionais que são capazes de auxiliar na construção do conhecimento [3], e podem ser usadas para ressignificar o conhecimento mediante significados claros, estáveis e diferenciados, previamente existentes na estrutura cognitiva do aprendiz [4]. A essência do processo de aprendizagem significativa é que as idéias expressas simbolicamente, são relacionadas às informações previamente adquiridas pelo aluno através de uma relação não arbitrária e substantiva (nãoliteral). Esta relação significa que as idéias são relacionadas a algum aspecto relevante existente na estrutura cognitiva do aluno, como por exemplo, uma imagem, um símbolo, um conceito, uma proposição, já significativo [15]. Segundo David Ausubel, a aprendizagem significativa só ocorre quando o material a ser aprendido é "ancorado" em conceitos relevantes já existentes na estrutura cognitiva do aprendiz. Por este processo, a nova informação interage como uma estrutura de conhecimento específica, chamada subsunçor. Quando o material aprendido não consegue ligar-se a algo já conhecido, Ausubel chama de aprendizagem mecânica, onde as novas informações são aprendidas sem interagirem com conceitos relevantes existentes na estrutura cognitiva.

A teoria da aprendizagem significativa é "uma teoria construtivista já que dá muita relevância às concepções prévias de cada aprendiz e considera a sua operacionalização uma construção pessoal e idiossincrática" [16].

Por ser uma ferramenta cognitiva para auxiliar a internalização de conhecimento simbólico, o Modellus [17] corrobora a visão sobre o processo de aprendizagem que fundamenta a utilização de softwares de caráter exploratório. Provê uma representação múltipla, onde o usuário pode criar, ver e interagir com as representações analíticas, analógicas e gráficas dos objetos matemáticos [18]. Do ponto de vista educacional, incorpora tanto o modo expressivo, onde os alunos constroem seus próprios modelos a as formas de representa-los; quanto o modo exploratório utilizando atividades modeladas por outros [18].

O uso do Modellus, como ferramenta cog- 
nitiva mediadora, aplicada no ensino médio à disciplina de Física, foi o objeto desta pesquisa.

\section{EXPERIMENTO}

A população alvo desta pesquisa foi formada por 91 alunos da $1^{\mathrm{a}}$ e da $3^{\mathrm{a}}$ série, ambos os grupos do ensino médio do Colégio Militar de Salvador - BA. Incluído no contexto de escola pública, esta Instituição de Ensino possui unidades em todas as capitais da federação do território nacional. A investigação ocorreu durante o segundo semestre, e na $3^{\mathrm{a}}$ unidade do ano letivo de 2005, na qual estavam previstas 28 horas/aulas de práticas laboratoriais como atividades da disciplina de Física.

O projeto pedagógico da Instituição de Ensino prevê o uso de Laboratório Virtual de Física, como forma de promover uma educação interdisciplinar, participativa e contextualizada.

O Modellus foi utilizado como Ambiente Virtual de Aprendizagem, uma vez que tem se tornado uma ferramenta de prática constante nas pesquisas em educação em ciências [19]. Instalado em um laboratório de informática, composto por 25 computadores, foram modeladas as seguintes atividades:

- Lançamento horizontal;

- Queda livre;

· Pêndulo simples;

- Conservação de energia.

De sistemas relacionados matematicamente com o tempo e quantidades físicas, estas animações dinâmicas e exploratórias, possibilitaram o uso dos recursos do software. Os conteúdos trabalhados, assim como a interação das atividades com os alunos, receberam mediação do corpo docente da Seção de Física do Colégio.

Para Lüdke [20, 21], a pesquisa qualitativa se propõe a interpretar as informações, de uma forma ampla, dentro do contexto no qual o problema de pesquisa está inserido. Envolve, também, a obtenção de dados predominantemente descritivos, enfatizando mais o processo do que o produto e se preocupando em retratar a perspectiva dos participantes da situação investigada.

Durante as atividades, os alunos trabalharam os seguintes aspectos da aprendizagem exploratória:

- Visualização de gráficos e conseqüente interpretação;

- Observação das trajetórias dos movimentos;

- Análise vetorial das simulações;

- Interpretação matemática das representações gráficas, analíticas e analógicas;

- Análise das relações entre as grandezas.

Na primeira simulação, apresentada na Figura 3, é realizado o lançamento simultâneo de duas esferas, uma lançada horizontalmente e outra verticalmente, a partir de uma mesa. É possível acompanhar, conjuntamente, o movimento da trajetória das partículas, onde são visualizados os vetores da velocidade, peso e aceleração. Ainda, na Janela de Animação, também se pode observar o alcance final do objeto assim como o valor da velocidade inicial do lançamento $\left(V_{0}\right)$. Em outra janela, de Condições Iniciais, foi possível aos alunos modificarem os valores, tanto da velocidade inicial quanto da massa das esferas, com isso possibilitando a interação do sujeito com o modelo e conseqüente percepção dos fenômenos.

Na Janela Modelo, que acompanha todas as atividades, estão indicadas as equações dos modelos dos movimentos que foram criados para cada uma das animações aplicadas na pesquisa.

A segunda simulação, conforme Figura 4, é o lançamento em queda livre de uma partícula. Nela, a trajetória do movimento de queda, o vetor velocidade, a altura, os tempos nos intervalos de queda e os gráficos são apresentados de forma simultânea para os alunos. A 
variação da energia cinética, da energia potencial gravitacional e da velocidade de queda, todos em função do tempo de queda, formam os três gráficos da Janela Animação. Também, na Janela Gráficos, é possível que o aluno selecione as variáveis que deseja verificar graficamente o comportamento em função do tempo. Na Janela Condições Iniciais é possível interagir, modificando os parâmetros da massa e da aceleração da gravidade.

A interatividade nas animações se mostra importante uma vez que permite ao aluno fazer representações, explorando-as sobre as mais diversas perspectivas [3]. Para Ausubel [15], preencheriam o hiato entre aquilo que o aprendiz já conhece e o que precisa conhecer antes de poder aprender significativamente a tarefa com que se defronta, permitindo oferecer uma orientação ideativa para a incorporação estável e retenção do material mais detalhado e diferenciado que se segue no texto a aprender.

A terceira simulação, apresentada na Figura 5, descreve a trajetória de um pêndulo simples, juntamente com as forças que atuam sobre este sistema. Os vetores velocidade e aceleração também são alvos de observação no sistema pêndulo da Janela Animação. É perceptível ao aluno observar a oscilação entre as Energias Cinética, $E_{c}$, e Potencial Gravitacional, $E_{p}$, que incidem no fenômeno. À medida que o ângulo do fio com o eixo vertical do sistema vai decrescendo, $E_{c}$ aumenta e $E_{p}$ diminui; por conseguinte, quando cresce, $E_{c}$ diminui, e $E_{p}$ aumenta, onde $E_{c}$ corresponde a energia cinética e $E_{p}$ a energia potencial gravitacional. É possível visualizar, através da Janela de Gráficos, a fotografia do movimento.

$\mathrm{Na}$ quarta simulação, Figura 6, criamos um circuito de conservação de energia, o qual chamamos de "circuito massa-mola-planoinclinado". Uma partícula é lançada a partir da compressão de uma mola, percorre um plano horizontal e prossegue continuamente o movimento em um plano inclinado. Três momentos são caracterizados na animação: ponto "A", onde a mola está comprimida pela esfera; ponto "B", que é o instante antes do início do movimento de subida do plano inclinado; e ponto "C", com o final da trajetória já no plano inclinado. É possível verificar o valor da energia nos pontos "A", "B" e "C" nesta seqüência: energia elástica, cinética e potencial gravitacional; a velocidade da partícula, no ponto "B"; distância percorrida no plano inclinado; altura alcançada, além dos valores iniciais das seguintes grandezas: constante elástica $(k)$, deformação da mola (d), massa da esfera $(m)$ e aceleração da gravidade $(g)$. Foram inseridos na animação aceleradores, os quais permitem que o aluno possa interagir com a simulação, modificando, em tempo de execução, os valores de $k, d, m, g$. Desta forma, podem perceber como e quais grandezas variam em função desses aceleradores.

Em todas as atividades, ao aluno é apresentada a possibilidade para modificar as grandezas e observar as múltiplas representações das atividades: gráficos, tabelas, animações e modelos matemáticos.

\section{APRESENTAÇÃO E DISCUSSÃO DOS RESULTADOS}

A pesquisa utilizou a inquirição como técnica de coleta de informações [22], para avaliar a atitude dos alunos em relação aos objetos de aprendizagem. Foi elaborado um questionário contendo 5 questões: três utilizando escala de atitude do tipo Likert [5]; e duas de levantamento de opinião, onde foram indagadas informações específicas sob forma de questão única. Na escala do tipo Likert, dá-se aos sujeitos uma proposição e eles devem expressar sua posição sobre a declaração que ela contém. Para cada declaração, os sujeitos são solicitados a indicar sua atitude em relação a ela e o grau em que são afetados. Pede-se que assinalem suas respostas segundo a intensidade de sua concordância ou discordância.

Nas questões de levantamento de opinião, o questionário indaga apenas informações específicas sobre determinado assunto, apresentado sob forma de questões únicas. Cada indivíduo assinala a resposta que achar conveniente, representada por um sim ou não. Os resultados finais vêm expressos em porcenta- 
gens de pessoas que dão cada tipo de resposta. O questionário utilizado investigou os seguintes pontos:

a) Você tem dificuldades para entender os conceitos de Física, que são dados dentro da sala de aula? (Muito difícil, Difícil, Nem difícil nem fácil, Fácil, Muito fácil).

b) Você acha que o uso de um Laboratório Virtual, facilita o entendimento da Física? (Não facilita nada, Não facilita, Tanto faz, Facilita sim, Facilita muito).

c) Você já usou o computador da sua casa para realizar alguma experiência da disciplina de Física? (Sim ou Não).

d) Você acha importante o colégio ter um Laboratório Virtual para realizar experiências, pesquisa e animações de Física no computador? (Não importante, Pouco importante, Tanto faz, Importante, Muito importante).

e) Que outra disciplina você acha importante usar o computador para realizar experiências e animações? (Matemática, Química, Biologia, Outras, Qual?).

A questão "a" foi respondida antes do começo das atividades com o Modellus. A Figura 7 indica que mais de $50 \%$ dos alunos possuem dificuldades significativas no aprendizado da Física, enquanto que apenas $6 \%$ não encontram dificuldades na disciplina.

Para Fiolhais e Trindade [23], o elevado número de reprovações na Física, nos vários níveis de ensino e em diferentes países, mostra bem as dificuldades que os alunos encontram na aprendizagem dessa ciência. A não utilização de meios mais modernos constitui uma das razões do insucesso na aprendizagem da Física. Também são apontados problemas metodológicos no ensino, insuficiente desenvolvimento cognitivo dos alunos, preparação matemática e pré-existência de concepções relacionadas com o senso comum e não com a lógica científica [24].
Na questão "b", a partir da Figura 8, observa-se que $64 \%$ dos alunos encontraram grande facilidade no entendimento da Física ao utilizarem o Modellus como ambiente virtual de aprendizagem. A utilização de software apropriado, para além do apoio computacional na realização de experiências e na apresentação audiovisual, pode facilitar o ensino e estimular a aprendizagem. Para Tao [25], os computadores modernos oferecem, inegavelmente, um grande número de possibilidades para ajudar a resolver alguns problemas concretos do ensino das ciências.

A Figura 1 demonstra que apenas $3 \%$ dos alunos já utilizaram o computador doméstico para algum tipo de simulação ou animação, objetivando o aprendizado da Física. Pedagogicamente, se o aluno não for estimulado, na escola, a interagir com um ambiente tecnológico de ensino e aprendizagem capaz de modificar e acrescentar significados, poucas serão as chances deste mesmo realizar atividades de simulação virtual dos fenômenos físicos em casa. Mesmo o aluno conhecendo inúmeras formas e técnicas de utilização de um computador doméstico, sejam elas comunidades de relacionamento, "emails", navegação, busca, jogos, "chats" e "downloads", ainda assim é muito provável, conforme Figura 1, que ele ainda não tenha executado ou observado, se quer, um exercício ou fenômeno da Física no computador de casa.

Segundo Mucchielli [26], os principais problemas associados ao uso dos computadores são de natureza material e pedagógica. De ordem material, destaca-se o fato que a maioria dos estabelecimentos escolares (principalmente as escolas públicas) não possui computador suficiente para os alunos nas aulas.

Observando a Figura 9, é possível perceber o grau de importância, para os alunos, da existência de um laboratório virtual para o ensino da disciplina de Física.

Uma outra preocupação da pesquisa foi investigar quais disciplinas despertavam o interesse dos alunos, em utilizar um ambiente virtual de ensino e aprendizagem. A Figura 2 apresenta quais foram essas disciplinas e seus respectivos percentuais. A legenda "outras" se refere às sugestões, as quais: Ge- 
ografia, História e Português estavam entre elas. Observa-se uma tendência maior, uma expectativa crescente com relação à disciplina de Química. Não foi investigado o porquê deste percentual elevado, mas tal índice justifica e constitui objeto de pesquisas futuras.

\section{CONSIDERAÇÕES FINAIS}

Apesar da grande quantidade de simulações e animações interativas que são possíveis de serem encontradas na rede mundial de computadores, poucos são os relatos do uso, de forma contextualizada, no ensino/aprendizagem de Física aplicada no ensino médio. Importantes Instituições de Ensino trabalham com pesquisas e Núcleos de Construção de Objetos de Aprendizagem, que buscam atender uma demanda para construção de animações interativas de Física.

As dificuldades naturais do ensino tradicional de ciências relacionadas às representações dos fenômenos, os poucos laboratórios existentes e o ensino exclusivamente instrucionista, parecem distanciar e desmotivar o aluno do ensino médio. Este, mesmo que já possua um conhecimento prévio sobre tecnologia da informação, no que tange a utilização de "sites" de relacionamento e busca, "chats", "email", "blogs" e "flogs", não encontra, na escola, ambiente capaz de aproveitar este conhecimento já adquirido e tão utilizado na rotina diária.

Utilizamos o Modellus como ferramenta computacional pedagógica de forma a mediar o ensino e aprendizagem da Física, buscando diminuir esta distância tecnológica entre a escola e o aluno. Buscou-se, também, com a pesquisa promover a interatividade do aluno com o objeto de conhecimento produzido, como forma de construção de uma aprendizagem significativa.

Durante as aulas no Laboratório Virtual de Física, foi notório e relevante o interesse dos alunos pela disciplina, na busca da compreensão dos experimentos, conceitos, interpretação gráfica, mudança de variáveis, levantamento de hipóteses e estímulo à pesquisa.
Em resumo, nossos resultados mostram que o uso do Modellus como ferramenta mediadora do ensino de Física, obteve uma aceitação acima dos $90 \%$ entre os alunos pesquisados. Com isso, entendemos que o uso de Ambientes Virtuais de Aprendizagem, contextualizados com a educação em ciências, se torna uma linguagem de fácil entendimento para alunos do ensino médio e objeto facilitador aos professores.

\section{APÊNDICE - FIGURAS}

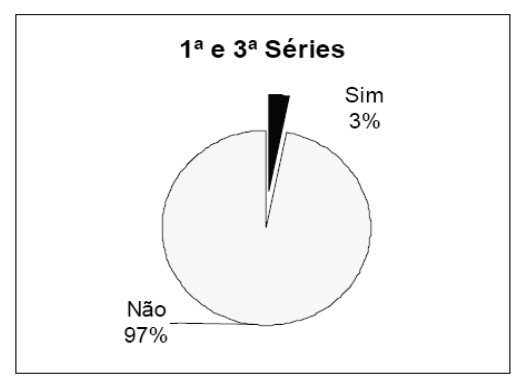

FIGURA 1: Percentual dos alunos que já utilizaram o computador doméstico para algum tipo de simulação ou animação, objetivando o aprendizado da Física.

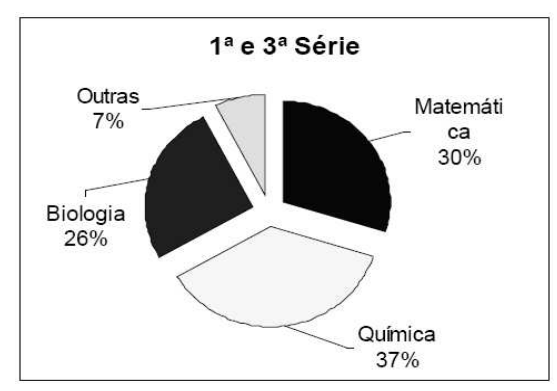

FIGURA 2: Resultado da investigação sobre quais disciplinas despertavam o interesse dos alunos em utilizar um ambiente virtual de ensino e aprendizagem. 


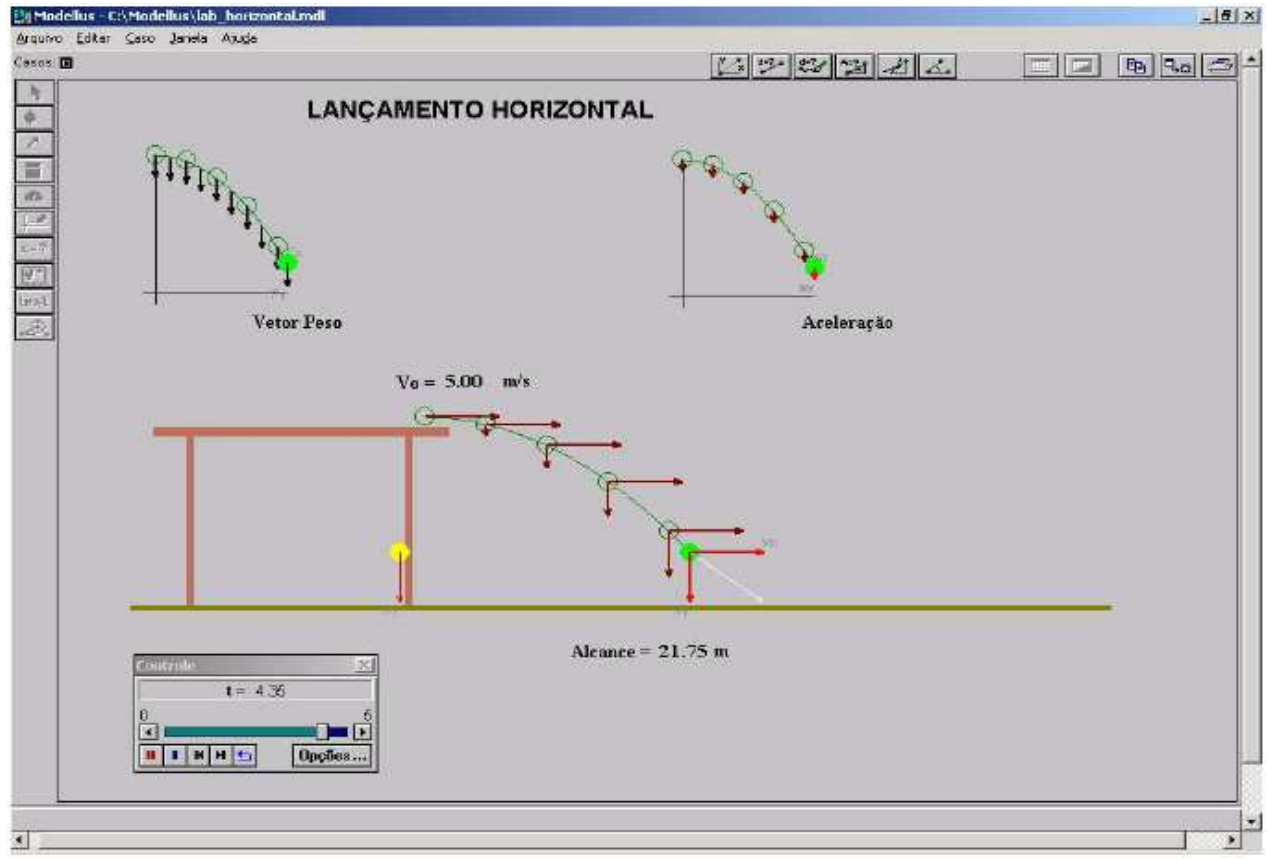

FIGURA 3: Tela do Programa "Modellus" na simulação do Lançamento Horizontal.

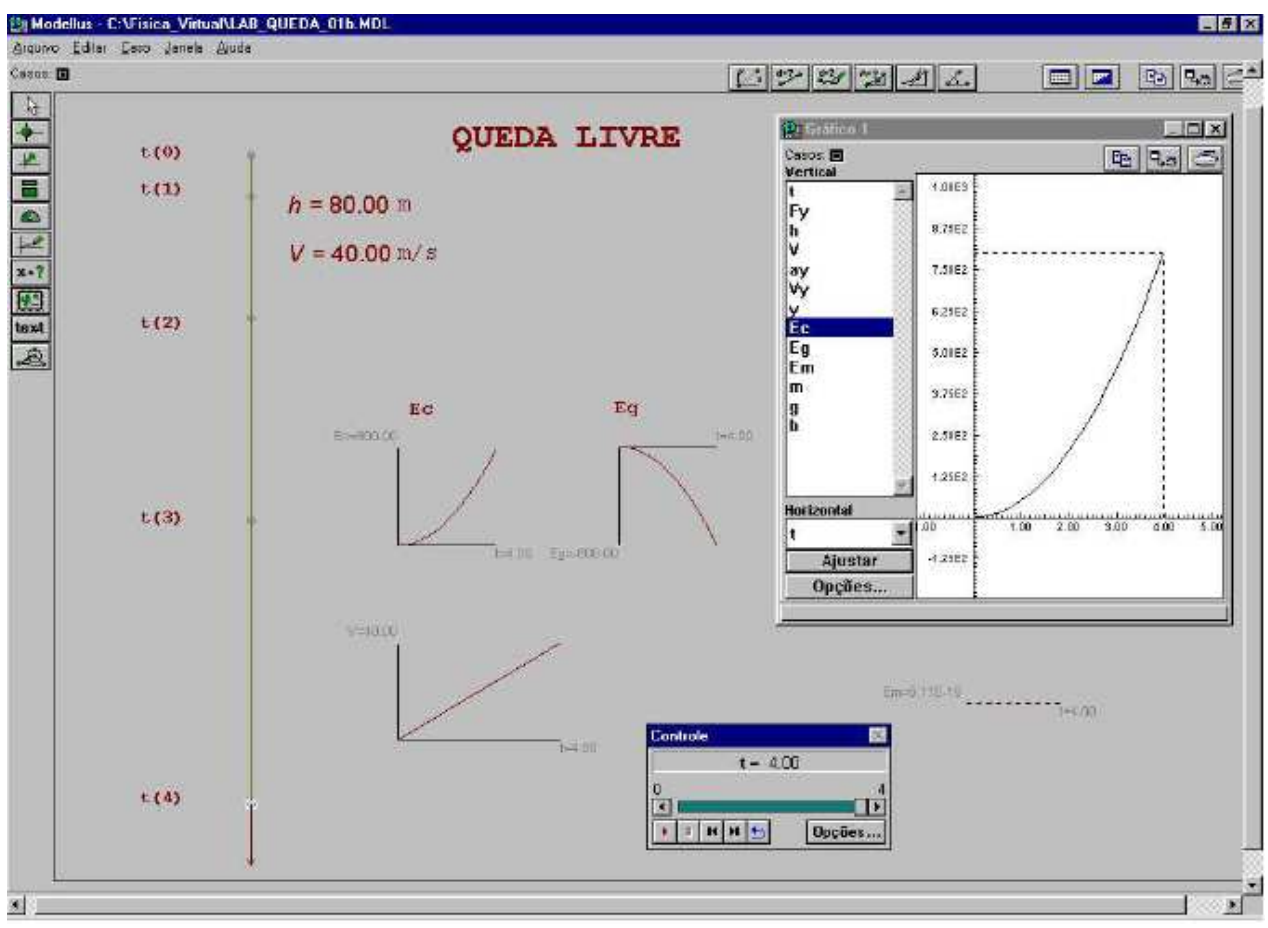

FIGURA 4: Tela do Programa "Modellus" na simulação da Queda Livre. 


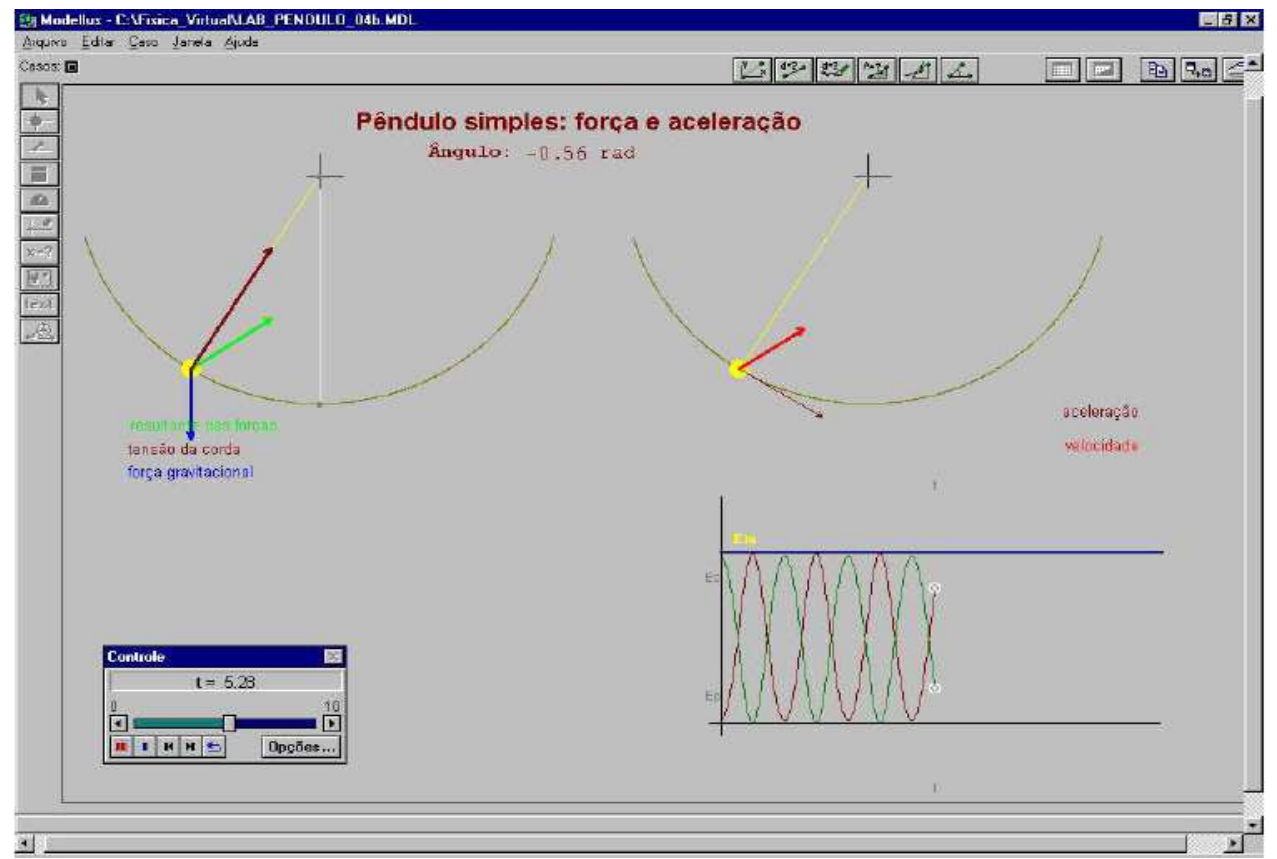

FIGURA 5: Tela do Programa "Modellus" na simulação do Pêndulo Simples.

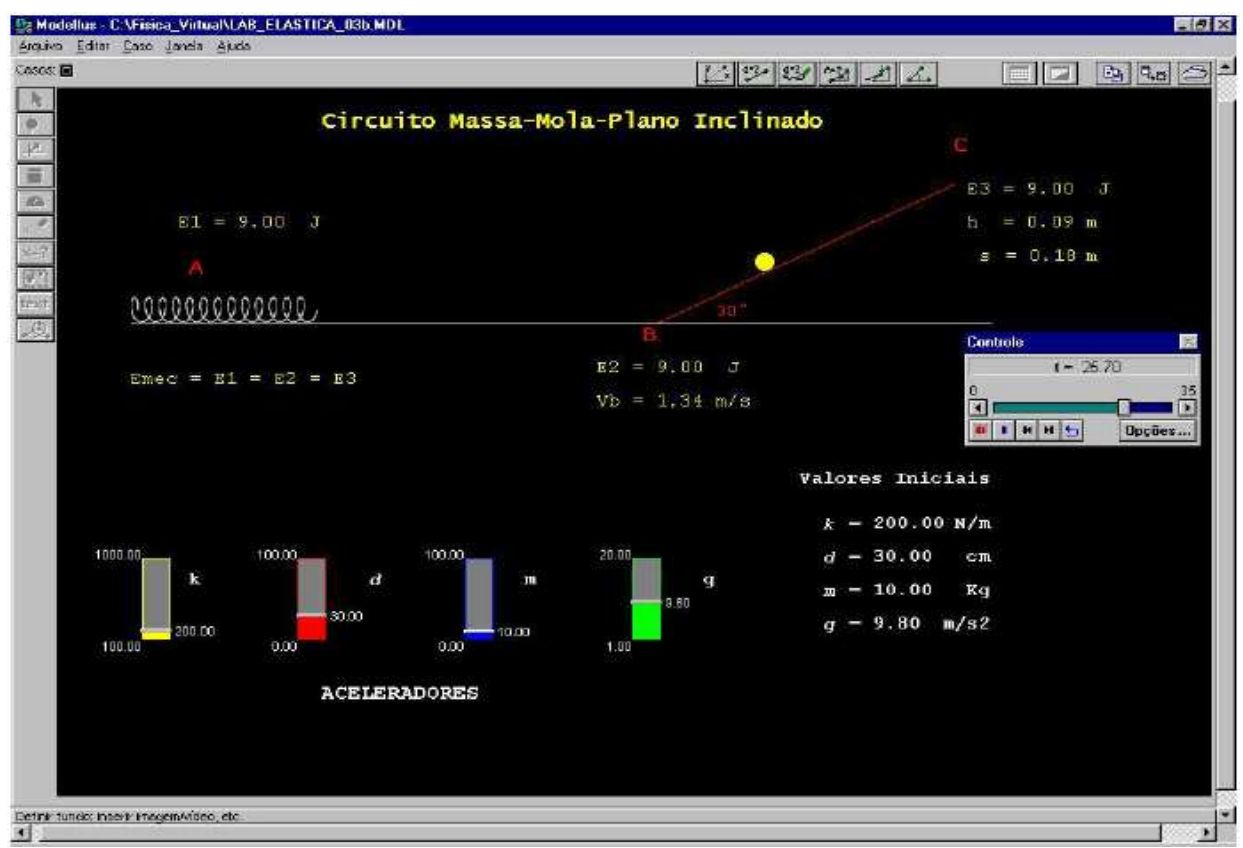

FIGURA 6: Tela do Programa "Modellus" na simulação do Circuito Massa-Mola-PlanoInclinado. 

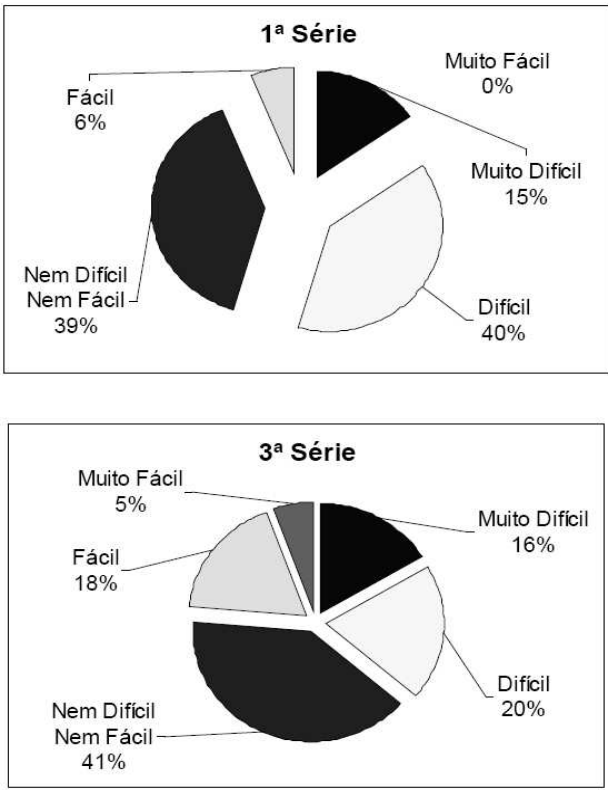

FIGURA 7: Questão "a" - Sobre a dificuldade para entender os conceitos de Física que são dados em sala de aula.
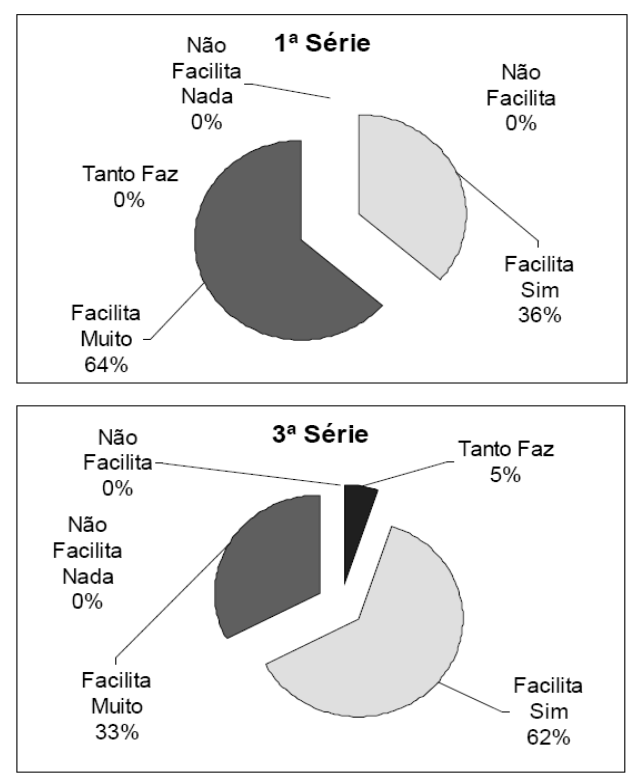

FIGURA 8: Questão "b" - Facilidade no entendimento da Física ao utilizarem o Modellus como ambiente virtual de aprendizagem.
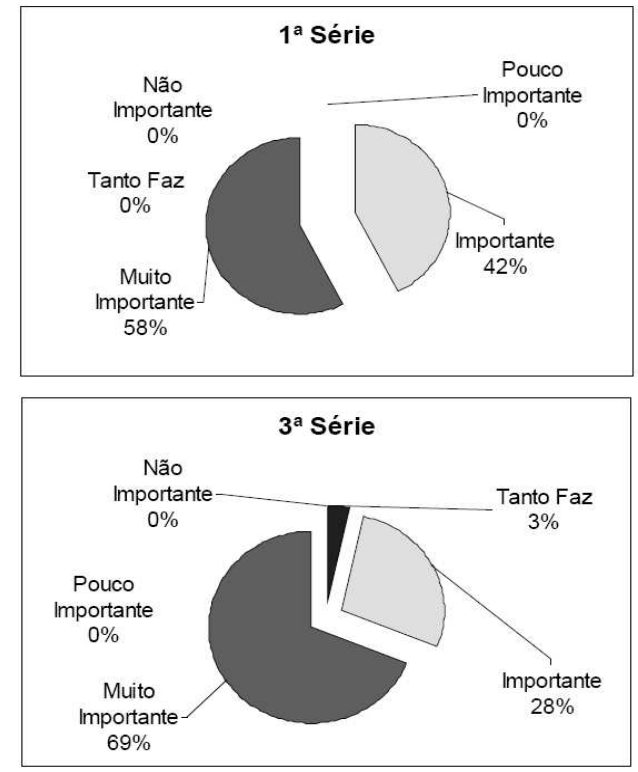

FIGURA 9: Grau de importância, para os alunos, da existência de um laboratório virtual para o ensino da disciplina de Física. 
[1] D. Hestenes, Am. J. Phys. 55, 440 (1987).

[2] R. Lawson, L. McDermott, Am. J. Phys. 55, 811 (1987).

[3] E.A. Veit, V.D. Teodoro, Modelagem no Ensino/Aprendizagem de Fúsica e os Novos Parâmetros Curriculares Nacionais para o Ensino Médio. Rev. Bras. Ens. Fis. 24, 87 (2002).

[4] M.A. Moreira, Teorias da Aprendizagem. São Paulo: EPU (1999).

[5] T.C. Erthal, Manual de Psicometria. Rio de Janeiro: Jorge Zahar Editor (2003).

[6] A.T. Borges, O Papel do laboratório no ensino de ciências. Belo Horizonte: Colégio Técnico da UFMG (1996).

[7] M.A. Moreira, Pesquisa básica em educação em ciências: uma visão pessoal. In: Congresso Iberoamericano de Educação em Ciências Experimentais, $1^{\circ}$, 1998. La Serena (1998).

[8] M.A. Moreira, C.E. Levandowski, Diferente abordagens ao ensino de laboratório. Porto Alegre: EDUFRGS (1983).

[9] G. Booch et al., UML guia do usuário. Rio de Janeiro: Campus (2000).

[10] P. Lévy, Cibercultura. São Paulo: Editora 34 (1999).

[11] I. Halloun, Schematic Modeling for Meaningful Learning for Physics. J. Res. Sc. Teac. 33, (9) (1996).

[12] C.H.J. Davies, Student engagement with simulations: a case study. Computers \& Education 39, 271 (2002).

[13] A. Jimoyiannis, V. Komis, Computer simulations in physics teaching and learning study. Computers \& Education 36, 183 (2001).

[14] J.N. Santos, R. Tavares, Animação interativa como organizador prévio. In: Simpósio Na- cional de Ensino de Física, 15², 2003. Curitiba (2003).

[15] D.P. Ausubel, J.D. Novak, H. Hanasian, Psicologia Educacional. Rio de Janeiro: Interamericana (1980).

[16] D. Gowin, Bob Educating. New York: Cornell University Press (1981).

[17] Página WEB: http://phoenix.sce.fct.unl.pt/modellus/ (gratuito).

[18] V.D. Teodoro. In: Internacional CoLos Conference New Network Based Media in Education. Slovenia (1988).

[19] L.A.C. da Costa, Ambientes Virtuais de Aprendizagem e suas Possibilidades Construtivistas. In: Congresso Global de Educação em Engenharia e Tecnologia, 2005. Santos (2005).

[20] M. Ludke, M.E.D.A. Andre, Pesquisa em Educação: abordagens qualitativas. São Paulo: EPU (1986).

[21] O.S. Trivin, N.S. Augusto, Introdução à pesquisa em ciências sociais: pesquisa qualitativa em educação. São Paulo: Atlas (1987).

[22] Z.D. Mediano, Módulos instrucionais para medidas e avaliação em Educação. Rio de Janeiro: Francisco Alves (1978).

[23] C. Fiolhais, J. Trindade, Fúsica no Computador: o Computador como uma Ferramenta no Ensino e na Aprendizagem das Ciências Físicas. Rev. Bras. Ens. Fis. 25, (3) (2003).

[24] A. Champagne, L. Klopfer, J. Anderson. Am. J. Phys. 48, 1074 (1980).

[25] P. Tao. Comp. Phys. 11, 199 (1997).

[26] A. Muchielli, O Ensino por Computador. Lisboa: Editorial Notícias (1988). 